\title{
A question of demand and supply? Defining the demand and providing a supply of respirologists
}

$\mathrm{I}^{\mathrm{n}}$ n this issue of the Canadian Respiratory Journal, we are invited to think about respirology manpower in Canada. I believe it is the first time that the Journal has published on the topic, perhaps suprisingly, for the issues that are raised are of great importance to all physicians who care for patients with chest problems. Dr Don Cockcroft and Dr David Wensley (pages 451-455) conducted a survey of program directors and obtained data regarding Royal College Fellows, which allowed them to estimate the number of chest specialists currently in practice and to predict what will happen to these numbers in the foreseeable future. Based on the numbers and the waiting times for outpatient appointments, their main conclusions are that there is a shortfall in adult respirologists that may be as high as $50 \%$; that the shortfall is at least as large for pediatric specialists; and that current output from training programs is unlikely to meet the shortfalls. Currently, they estimate a total of 361 adult specialists, or one for every 86,000 population, but with regional differences that account for a variation from one to 69,000 in Alberta to one to 253,000 in New Brunswick.

It is interesting that the British Thoracic Society has gone through a similar exercise (www.brit-thoracic.org.uk), although the data are not as well organized as those provided by Cockcroft and Wensley. The author, Dr Jonathan Turner, identified two target ratios - one recommended in a position statement of the Royal College of Physicians (Working for Patients II 1999) that is similar to the one existing in Canada of one to 80,000, and one based on the average number for the European Community of one to 60,000. His report identifies the total number in England and Wales as 468, or one to 149,000 , if I have not misunderstood the data. He quotes a current increase of about $5 \%$ per year and notes that this percentage needs to be doubled if the target of the Royal College of Physicians is to be met by 2006. Thus, the shortage in the United Kingdom is dramatic and may lead us to feel we are much better off in Canada than our counterparts in the United Kingdom. However, there may be reasons for us to be less sanguine.

The first reason relates to geography. I have had to con- sider the issue of manpower requirements many times in the past 30 years or so, probably dating from the time that Dr Colin Woolf approached program directors in the early 1970s for their views as he worked on his report on the topic. At the time, it was my feeling that the problems in Canada appeared unique, and that a

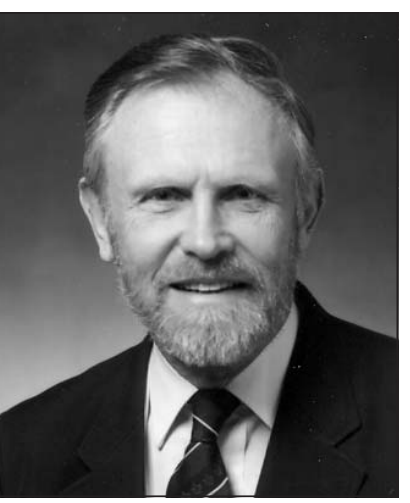
calculation of the number of respirologists per 100,000 population and related to studies carried out in other countries probably would be inadequate to provide a realistic estimate; after reading Dr Cockcroft's report, I still feel this. At the time of Dr Woolf's request, I sat down with a large map of Ontario and a copy of the Canadian Medical Directory; it was abundantly clear that there could be more than 100 miles between district hospitals with intensive care units. In the United Kingdom, it would probably be hard to find any two such hospitals more than 30 miles apart. Similarly, there are many communities in Canada in which patients have to travel for more than $3 \mathrm{~h}$ to reach a hospital, and longer to reach a referral hospital, with specialty services. Such differences are bound to have implications for the need for specialist respirologists in a given hospital. Recently, Boris Kralj of the Ontario Medical Association's Economics Department formalized and quantified the process by developing a 'rurality index' for Ontario (1). Components of the index include travel times to the nearest referral centre and to the nearest advanced referral centre, population density and a weather factor. The results showed the expected poor access to medical facilities in northern Ontario, but also showed that a similar or worse situation exists in many communities in southwestern parts of the province (1). Doubtless other parts of the country fare as badly or worse.

Aside from geography, perhaps we need to define what 
respirologists do. Cockcroft and Wensley found that many spend appreciable time in other disciplines. Furthermore, their skills, for example in intensive care or bronchoscopy, and other facets of their work are shared with other specialty groups, such as anesthetists and thoracic surgeons. However, from the point of view of defining the need for respirologists in a given hospital or community, there are two factors that may ease the task. First, we are fortunate that training requirements for specialists are well set out in Canada, and, second, we have clinical guidelines and consensus statements for the investigation and management of the main respiratory disorders.

When we come to deciding the needs of a community, we will also need to agree on the roles of different physician groups in managing respiratory disorders, in particular, that of family physicians. In the United States, only $12 \%$ of physicians are in family practice but fewer than $15 \%$ of patients seen by specialists have been referred by other physicians, meaning that the specialists are providing primary care. By contrast, $65 \%$ of physicians in the United Kingdom are in family medicine, and a proportionately larger number of chest problems are managed by them with less help from specialists. No doubt, in Canada, as with many other issues, we hold a 'mid-Atlantic' position. However, as specialists, we should help family physicians to manage better asthma and chronic airflow obstruction, for example by encouraging the use of spirometry in their practices and helping them meet practice guidelines.

The data provided by Cockcroft and Wensley have to give us pause for thought; an approach to meeting the projected shortfall needs to be put in place urgently. I have no wish to muddy the waters but to stimulate some discussion (and perhaps some letters to the Editor!) on the demands for respirology services as a way of strengthening the case for increased training in the specialty.

Norman L Jones Editor-in-Chief

Canadian Respiratory Journal

\section{REFERENCE}

1. Kralj B. Measuring "rurality" for purposes of health-care planning: an empirical measure for Ontario. Ont Med Rev 2000;Oct:33-52. 


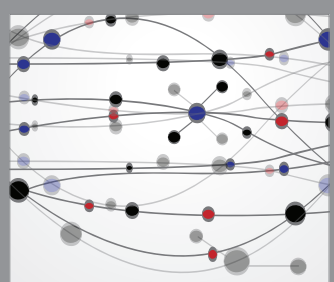

The Scientific World Journal
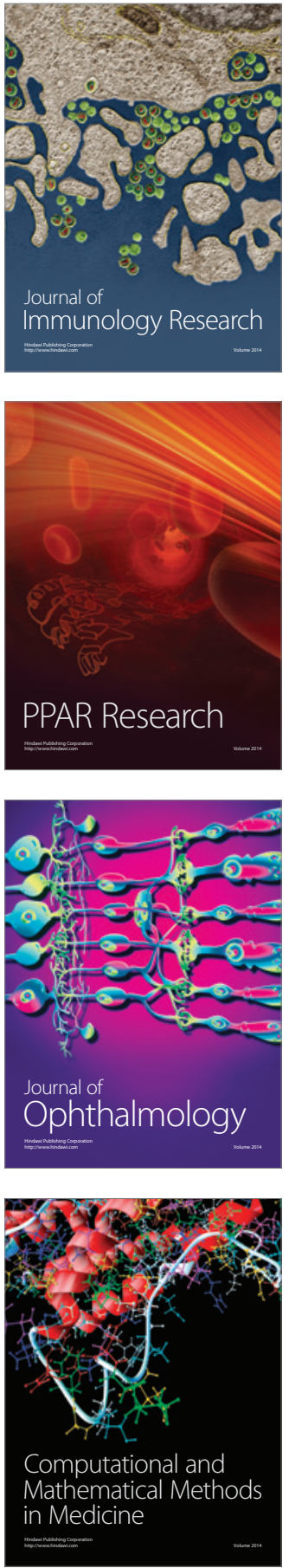

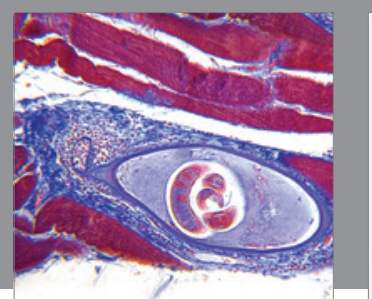

Gastroenterology Research and Practice

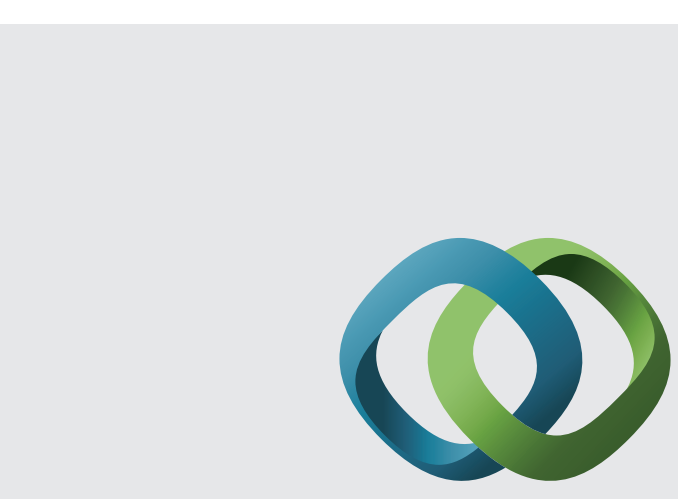

\section{Hindawi}

Submit your manuscripts at

http://www.hindawi.com
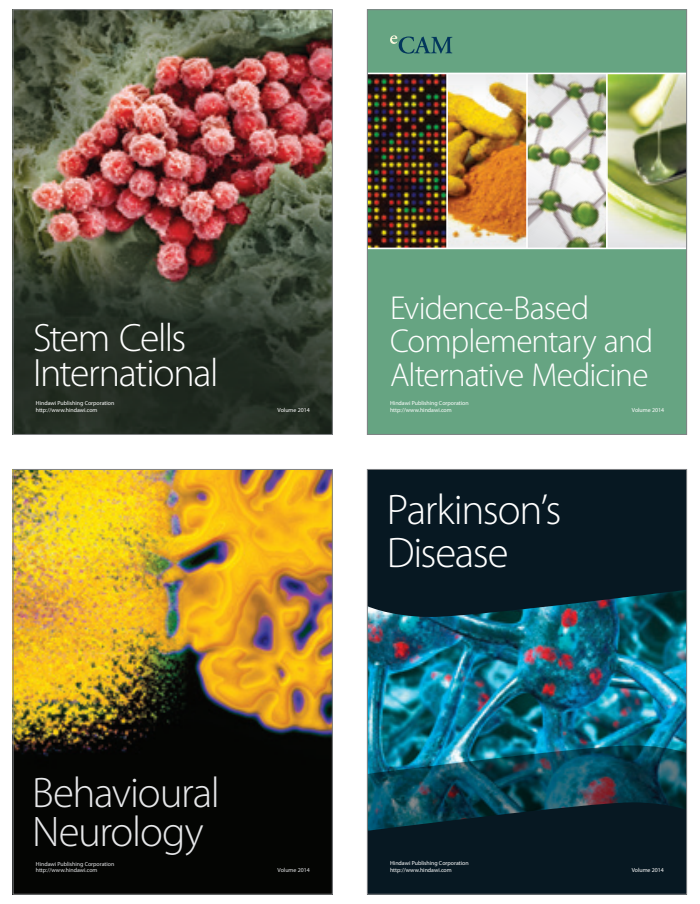
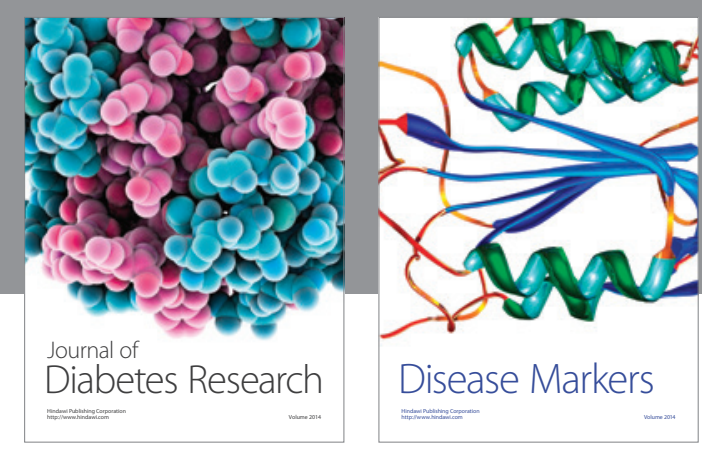

Disease Markers
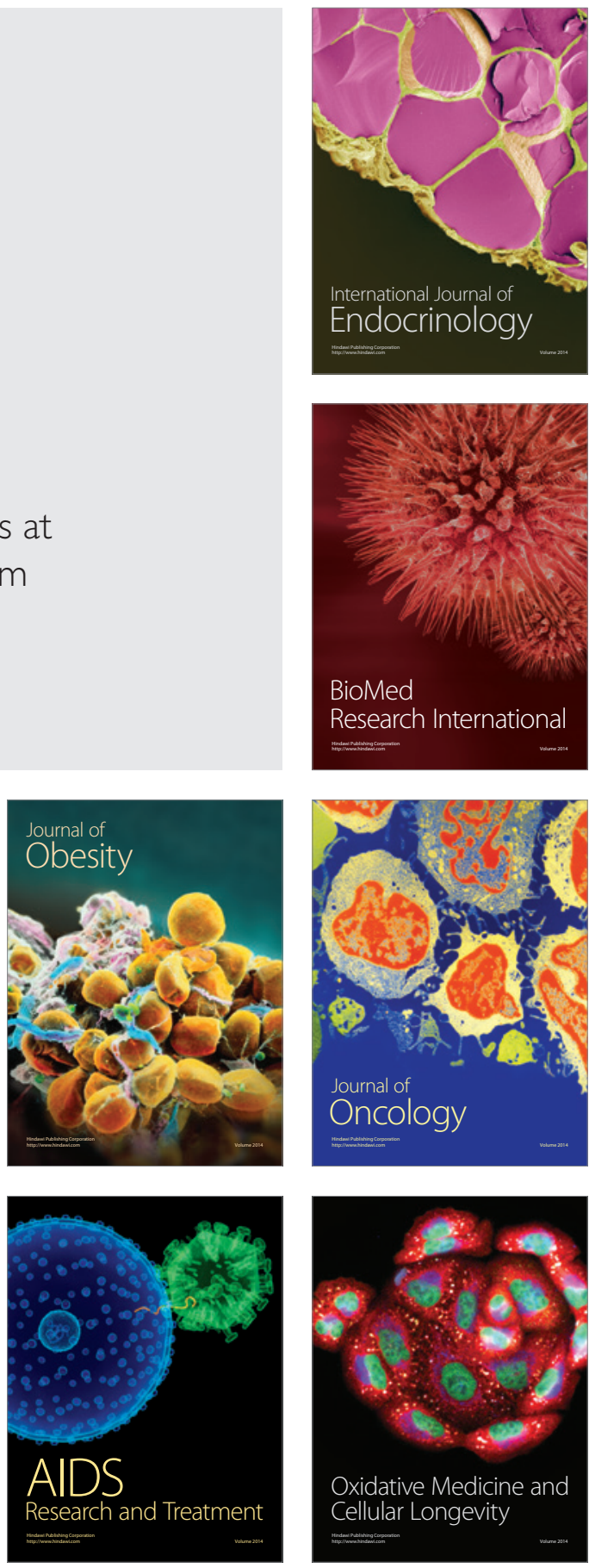